\title{
How can biases affect entrepreneurial decision making? toward a behavioral approach to unicorns
}

\author{
Gianpaolo Abatecola ${ }^{1}$ (D) Matteo Cristofaro ${ }^{1}$ (D) . Federico Giannetti ${ }^{1}$. \\ Johan Kask ${ }^{2}$ iD
}

Accepted: 30 September 2021 / Published online: 14 December 2021

(c) The Author(s) 2021

\begin{abstract}
How can cognitive biases affect the birth and evolution of entrepreneurial ventures? In Entrepreneurial Decision Making (EDM), this lively research question remains largely unaddressed when the world of Unicorns, as a per se entrepreneurial species, is considered. Thus, through this conceptual article, we aim to contribute toward knowledge creation in this context. We start by proposing a conceptual framework of Unicorns' EDM based on a behavioral approach. Through three propositions, this novel framework advances how the birth, transition, and consolidation of a Unicorn may be explained by the sequentially intertwined occurrence of biases, from which establishment and legitimization eventually emerge. We complement the framework with examples from the social media industry and then discuss its main implications for theory and practice.
\end{abstract}

Keywords Entrepreneurial decision making · Cognition · Biases · Unicorns · Conceptual

Gianpaolo Abatecola

abatecola@economia.uniroma2.it

Matteo Cristofaro

matteo.cristofaro@uniroma2.it

Federico Giannetti

federico.giannetti@uniroma2.it

Johan Kask

johan.kask@oru.se

1 School of Economics, Department of Management and Law, Tor Vergata University of Rome, Via Columbia 2, Rome, Italy

2 Örebro University School of Business, INTERORG Marketing Research Center, SE-701 82 Örebro, Sweden 


\section{Introduction}

How can cognitive biases (hereafter biases) affect the birth and evolution of entrepreneurial ventures? Research in entrepreneurship has been increasingly focused on analyzing Entrepreneurial Decision Making (EDM), commonly conceived by entrepreneurs as a decision-making process regarding opportunity recognition (i.e., through which individuals discover and recognize potential business opportunities), opportunity assessment (i.e., the evaluation of venture ideas according to certain parameters), and opportunity exploitation (i.e., activities conducted in order to gain economic returns from an entrepreneurial opportunity). Over time, it has become a matter of fact that EDM significantly concurs with the survival, success, or failure of new ventures (Shepherd, 2011; Soto-Simeone et al., 2020).

Since the works by Busenitz and Barney (1997) and Baron (1998), and also benefitting from the growing behavioral approach to entrepreneurship (Huang \& Knight, 2017; Murphy, 2011), the study of entrepreneurs' biases has constantly gained momentum in EDM (e.g., Caputo \& Pellegrini, 2019; Hallen \& Pahnke, 2016). For example, recent reviews (Shepherd et al., 2015) have highlighted that: $i$ ) entrepreneurs heavily rely on biases in their decision making more than managers of established firms and non-entrepreneurs; ii) biases are the product of cognitive-emotional intertwinement within and between decision makers; and iii) the occurrence of biases mainly depends on personal experience, an entrepreneur's social network, and personal capital. In this article, we use the word "bias" in its initial, conceptual meaning (Simon, 1947; Tversky \& Kahneman, 1974); thus, as an umbrella term, generally substantiating unconscious divergence from (at least intended) economic rationality in decision making.

The above introduced, the need to address some important questions around entrepreneurial biases now seemingly appears as pivotal (e.g., Omorede et al., 2015). In particular, according to Zhang and Cueto (2017), the implications of many biases in entrepreneurship are still unknown, together with the investigation of the interaction among biases, and also their multi-level link with other contextual and inner factors (e.g., prior experience). In summary, "the extent of the match between evolutionarily adapted mechanisms and the representations called for in entrepreneurial decision situations, become essentially the puzzle which entrepreneurship research should seek to untangle" (Shepherd et al., 2015: 22).

On this premise, this conceptual article aims to contribute to the calls above, elaborating on what EDM biases may occur when investors, firms' founders, and other important stakeholders are taking decisions that shape the birth and evolution of Unicorns. As we explain, the world of Unicorns, as a per se entrepreneurial species, appears to gain momentum when rationality and intuition in EDM processes are under investigation; in fact, notwithstanding their importance also at the macroeconomic level, Unicorns have been mostly the focus of venture capital perspectives (Acs et al., 2017; Aldrich \& Ruef, 2018). Conversely, although considered as central, the question of what cognitive mechanisms (and possible deviations from rationality) impact on their formation and growth still appears to remain largely unaddressed (Lehmann et al., 2019; Mollick, 2020). 
Against this backdrop, the core of this article, and its main contribution, lies in starting to develop a conceptual framework regarding EDM in Unicorns. Through three propositions, the framework advances how the birth, transition, and consolidation of a Unicorn may be potentially explained as the sequentially intertwined occurrence of biases. From these, establishment and legitimization eventually emerge. To do so, we first provide readers with our research background (Sect. 2), and context (Sect. 3). In Sect. 4, we develop our framework, which we also complement through examples from the social media industry. Finally, in Sect. 5, we discuss the main theoretical contribution of our research, together with its implications for the theory and practice of EDM.

\section{Research background}

How do entrepreneurs really make decisions? Since the works by Busenitz and Barney (1997) and Baron (1998), who are among the first to investigate cognitive mechanisms in EDM, the entrepreneurial literature has tried to bridge the gap with the studies about human cognition (Robinson \& Marino, 2015). In this regard, Baron (1998) advances entrepreneurs often work in situations and under conditions that would be expected to decrease rational behavior. Specifically, "they face situations that tend to overload their information-processing capacity and are characterized by high levels of uncertainty, novelty, emotion, and time pressure. Together, these factors may increase entrepreneurs' susceptibility to a number of cognitive biases" (p. 275).

Stemming from the above assumptions, a plethora of scholars soon become interested in the cognitive processes of entrepreneurs. For example, to explain opportunity evaluation, and conceiving it as an essentially cognitive phenomenon, Keh et al. (2002) propose a model that combines risk perception with four biases (i.e., overconfidence, belief in the law of small numbers, planning fallacy, and illusion of control). Through an empirical test on 77 owners of small and medium-sized enterprises in Singapore, and in contrast to Simon et al. (2000), these scholars prove that the belief in the law of small numbers bias directly influences opportunity evaluation without being mediated by risk perception. In practice, they demonstrate the presence of bounded rationality in EDM, showing that biases directly enter the process.

With the above introduced, a fast-growing amount of qualitative and quantitative research then attempts to deepen EDM through the adoption of a behavioral perspective (Hmieleski \& Baron, 2009; Krueger, 2003). In this regard, from a recent review of 156 articles from top-tier journals, Shepherd et al. (2015) assume that biases often occur in (and facilitate) EDM, especially when entrepreneurs estimate emerging challenges or opportunities through predictions. For example, entrepreneurs apparently show high levels of optimism (which leads to increased effort in their new ventures), overconfidence (which leads to entering industries despite equivocal information, or expanding their venture despite negative market feedback), and reliance on experience (being heavily anchored on their prior beliefs). Thus, Shepherd et al. (2015) conclude by claiming that 
additional consistency is needed regarding the formation, use, and (also) potential benefits of biases (Gigerenzer \& Brighton, 2009).

Increasing interest in the behavioral study of biases in EDM has emerged even more recently. For example, through the qualitative investigation of a sample of 755 inventor-entrepreneurs, Adomdza et al. (2016) find that planning fallacy (i.e., predictions about how much time will be needed to complete a future task) usually increases funding amounts from investors, positively impacting a venture's future performance. Relatedly et al. (2016) provide a qualitative analysis of the interviews with 12 lead counsellors in US-based Small Business Development Center offices. They demonstrate that, when an entrepreneur wishes to begin the start-up process, biases are more likely to happen and impact the assessments of feasibility. In particular, the interviewed counsellors identify that a substantial (and increasing) number of individuals with inadequate skills, education, experience, and financial capital, whom they call wannabes or dreamers, "gravitate toward the lure of entrepreneurship, spurred on by their cognitive bias-induced inflated estimates of preparedness and ease of entry" (p. 58).

Drawing on a series of related works, Zhang and Cueto (2017) propose advancement in the study of biases in entrepreneurship. Specifically, through the consideration of the cognitive-emotional intertwinement among decision makers, they reclassify the biases emerging from 41 EDM articles according to the following three categories:

a) make-happy biases. These lead people to: "selectively expose themselves to evidence and assimilate positive evidence, happily neglecting neutral or negative evidence" (Zhang \& Cueto, 2017: 11), tend to reduce risk perception, and carry both positive and negative effects on performance. These biases mainly happen because of entrepreneurs' inexperience, young age, high environmental complexity/dynamism, riskiness of the contexts, and trust from others (Bernoster et al., 2020);

b) sketchy-attribute biases. These lead people to pay attention, within a decisionmaking context, to one attribute despite the fact there are others that are more relevant, tending to decrease risk perception (De Carolis \& Saparito, 2006). These biases mainly happen because of the entrepreneurs' social network and personal capital, due to the fact that they would enhance shared attitudes and mental models;

c) psycho-physics biases. These biases refer to the alteration in humans' perception of quantitative attributes; this is the least studied category among the three and there are no reported conclusive results.

Zhang and Cueto (2017) then ultimately posit a series of open avenues for the research in biases related to EDM. They stress the need to interpret biases according to the individual exemplifications of EDM, together with the need to match decision ecologies with the evolving cognitive processes which underlie them (Dew et al., 2008; Mitchell et al., 2002). 


\section{Context}

To contribute to the EDM lively debate about how biases can affect the birth and evolution of entrepreneurial ventures, theoretically elaborating on the world of Unicorns can add value because of (at least) two intertwined reasons, which we explain below. ${ }^{1}$

First, it is a matter of fact that, together with gazelles and Venture Capital-backed companies, Unicorns are significantly challenging the common perceptions traditionally associated with failure and liabilities for new ventures (Josefy et al., 2017; Soto-Simeone et al., 2020). Currently influencing the world economy, Unicorns are said to belong to a hot-growth start-up club (De Massis et al., 2016; Lee, 2013) ${ }^{2}$; becoming extraordinarily profitable and successful in a few years, they appear to be a niche that is far from the classical logic belonging to the seminal liability of newness (Stinchcombe, 1965).

Second, and however, to date the literature on these entrepreneurial species mainly lays in venture capital conversations, with insights provided by EDM scholars still being fragmented (Aldrich \& Ruef, 2018). This becomes particularly problematic if one searches for scholarly evidence about what cognitive mechanisms can affect the Unicorns' formation and growth (Acs et al., 2017; Lehmann et al., 2019); as for this precise line of inquiry, knowledge is seemingly almost absent. This is also why we concur with those few existing works (Cowden et al., 2020; Mollick, 2020), which claim that, to understand why and how Unicorns come to light and thrive, the behavioral dynamics behind their entrepreneur-to-investor relationship need to be properly understood. Specifically, we agree that this understanding becomes meaningful only through investigating if, what, and how biases can potentially influence this relationship.

Consequently, it seems that the existence of Unicorns themselves, as a per se entrepreneurial species, merits serious attention in terms of EDM. If we agree with the predominance of a rather deterministic evolutionary path for start-ups, we will still have difficulties in conceptually admitting the possibility that Unicorns exist (Aldrich \& Ruef, 2018). In this regard, as we know that the liability of newness construct (Stinchcombe, 1965) has had (and still has) a tremendous impact on the EDM research domain over the past 50 years (De Winnaar \& Scholtz, 2020). According to Stinchcombe (1965), most new-born firms face a period of truly Darwinian natural selection in the first years of their life cycle, with their mortality rates being dramatically high. Stinchcombe argues that the tremendous difficulties in start-ups'

\footnotetext{
${ }^{1}$ Unicorns, as known, are start-ups with a market value equal to over US\$1 billion, mainly because of their potential to disrupt a market creating a new paradigm through platforms and scalable business models (Stadler, 2016). Thus, the mythological animal used to depict these start-ups' typology is a rhetorical figure intended to symbolize the ecological rarity (almost absence) of such exceptional value for most start-ups in the first years of their life cycle.

2 According to Crunchbase (2020), to date only 491 active Unicorns exist worldwide, with a collective market value of about $\$ 1,539$ billion (the most valued is ByteDance with $\$ 140$ billion). Most Unicorns are located in the US (48\%) and China (24\%), with the most represented industries being Internet software and services (15\%), e-commerce (14\%), and fintech (12\%).
} 
infant survival mainly derive from the lack of customers' trust, the lack of the founders' prior experience, and the absence of effective and efficient intra-organizational routines.

On this basis, sometimes start-ups do not suffer high risk of being selected out of their competitive environment at the very beginning of their life cycle, but after a few years of existence. In those cases, the initial period of peace from competition threats is known as a honeymoon (Fichman \& Levinthal, 1991); the honeymoon can possibly occur because, at the beginning, the start-ups may have a bundle of assets, such as the favor of fascinated investors, which can countervail the environmental pressures towards their exclusion. The mortality/failure risk rises only when this initial buffer loses its positive effect. In this regard, however, many existing Unicorns seem to be far from, at least in the short term, suffering a real failure risk, thus their evolutionary path currently seems to fit neither with the theoretical conjectures of Stinchcombe (1965) nor with those of Fichman and Levinthal (1991).

In summary, the existing, widely accepted EDM theoretical frameworks explaining the initial years of the firms' life cycle seem to need at least some major rethinking where Unicorns are concerned; especially in those (many) cases in which net income, market valuation and, ultimately, survival chances, do not apparently move in the same direction (Cristofaro, 2017). For example, looking at social media, journalist and industry expert Brendan Gallagher notes: "It's important to reiterate again that the valuations are not the same as public companies' market caps. Venture capitalists invest in start-ups to hold their equity for years until the company goes public or gets acquired. The current valuation doesn't matter in the long run to investors. What matters is how the company grows and what percentage of the company the venture capitalists own. Hence, while a start-up might haggle over whether it should be valued at $\$ 80$ or $\$ 90$ million, a venture capitalist cares much more about whether his equity stake is 18 percent or 19 percent" (Gallagher, 2018: 44).

\section{Toward a behavioral approach to unicorns}

Figure 1 presents an initial attempt to provide the EDM audience with a behavioral framework showing the possible impact of biases on the birth and evolution of Unicorns as a per se entrepreneurial species. From the beginning, it is important to highlight that, in the vertical axis of Fig. 1, we insert those agents who, because of their shaping actions and input resources, mainly influence the evolution of newborn firms (Huang \& Pearce, 2015; Murnieks et al., 2011): i.e., founders and investors, both at the top of the figure. In parallel, drawing on Colombelli et al. (2019: 509), in the horizontal axis, we depict the stages of entrepreneurial evolution as: $i$ ) birth (i.e., "the emergence of an entrepreneurial setting"), ii) transition (i.e., "the emergence of a complex variety [...] of feedback mechanisms, which may support or discourage path dependence processes within the network of actors"), and iii) consolidation (i.e., players "have survived the adaptive life cycle and are well embedded in the context").

As depicted in Fig. 1, investors and founders are the main agents that influence the birth and growth of potential Unicorns over time. This influence, as we 


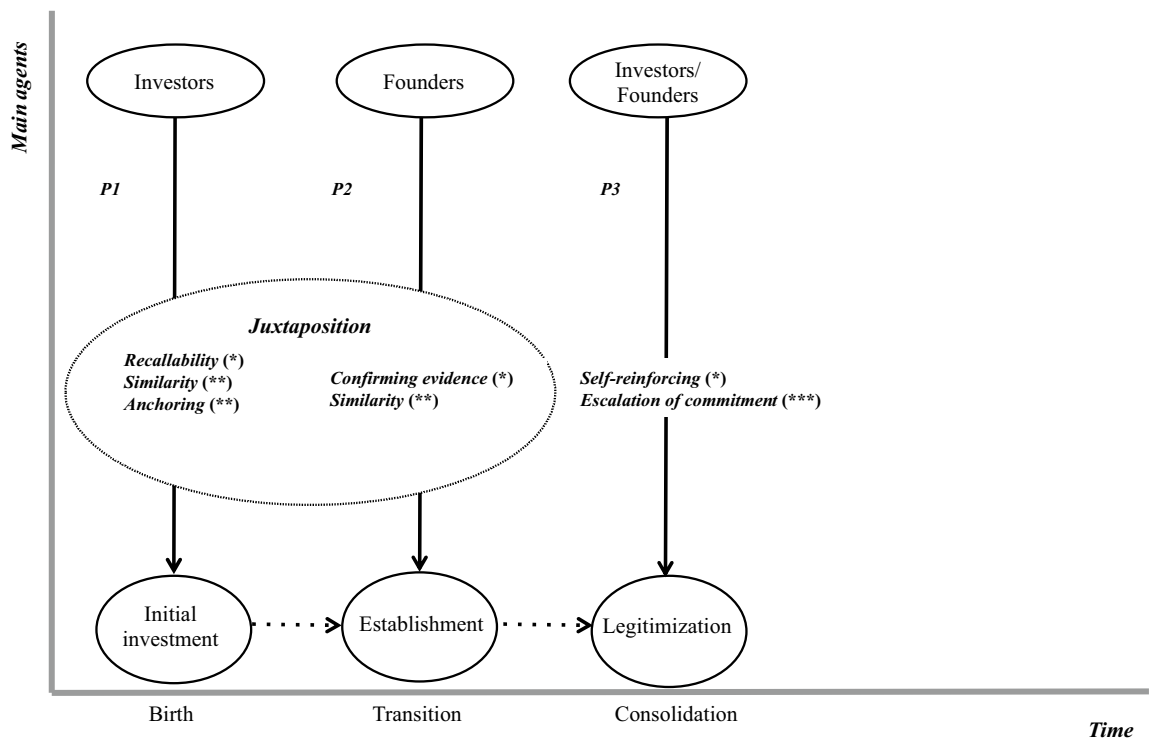

Source: Own elaboration.

Note: $(*)=$ Make-happy bias; $(* *)=$ Sketchy-attribute bias; $(* * *)=$ Psycho-physic bias.

Fig. 1 Birth and Evolution of Unicorns: Toward a Behavioral Framework

advance below, can gradually develop because of some sequential, intertwined biasing mechanisms between and among these interacting agents. In turn, we assume, these mechanisms can lead promising start-ups to their initial establishment and subsequent, eventual legitimization as Unicorns. Establishment is intended here as the shift of a firm from the status of "new entry in the market" (featured by high risk of exit) to that of "reputable and likely permanent player" (Klier et al., 2017). Legitimization, instead, is intended as the social act of building consensus among the industry audience. This consensus regards what features and behaviors the firm should have to be considered as appropriate and desirable, with the consequence of enjoying greater chances of survival (Pontikes, 2012).

\section{Stage I: birth}

As Tversky and Kahneman (1981) and Hammond et al. (1998) seminally identify, when making a decision people may recall the most vivid memories of a specific situation. This mechanism, which is a make-happy bias, is called recallability; it is often intertwined with similarity, which is a sketchy-attribute bias also extensively considered in EDM studies (Toft-Kehler et al., 2014). The latter substantiates the tendency: "to evaluate more positively those who are more similar to themselves" (Zhang \& Cueto, 2017: 9). Solicited by the similarity that the mind makes between two objects, these memories work as the main pieces of information on which the 
decision makers heavily rely (i.e., anchoring, another sketchy-attribute bias) to make their decision (Caputo, 2016).

On the above theoretical premise, at the birth stage of our proposed framework (Fig. 1), and similar to the framework by Fellows (2004) regarding options, evaluation, and choice, investors initially identify a set of promising start-ups, which form the possible choices for investments (also called options). Then, they evaluate each investment option through a process of juxtaposition, which essentially means placing two elements side by side and comparing them according to their similarities or differences. Specifically, at the birth stage investors try to recall the business features (e.g., a highly scalable business model through platforms) of other Unicorns within the same industry to find potential similarities with the promising start-ups under evaluation. Investors select the potential Unicorn by looking at various features, such as daily active users' growth, or network effects, which are different from those considered by these early-stage investors when evaluating standard businesses, i.e., revenue growth, value-added of product/service, the management team's track record, and profitability (Block et al., 2019). Because these pieces of information can work as anchors for investors, the promising start-ups can be chosen for initial investment. Therefore:

Proposition 1: At the birth stage, when investors juxtapose a promising start-up with past, successful Unicorns in the same industry, recallability, similarity, and anchoring can occur, leading to the initial investment.

As an example, in the social media industry, one start-up entering the exclusive Unicorns' club between 2015 and 2016 is Snapchat, founded in California in 2011. Experts have argued that, at the time of the first-round investments in this start-up, various investors might have recalled Facebook's business features, ${ }^{3}$ together with those of other already successful social media apps and might have looked for similarities with Snapchat to make an evaluation of the latter (Bloomberg Technology, 2017). For instance, as noted by Jeremy Liew (Lightspeed Venture, Snapchat's first investor): "Facebook is the journal of record for our real lives.... If you flip Facebook's need for permanence to impermanence, you get Snapchat" (Shontell, 2013). Likewise, in the words by Mitch Lasky (Benchmark Capital, another of Snapchat's important investors): "I started hearing Snapchat in the same context as Twitter, Instagram and Facebook. That got me curious [...] Snapchat's ramp reminded us of another mobile app that Benchmark had the good fortune to back at an early stage: Instagram" (Kern, 2013). Relatedly, when explaining why his important investment fund decides to invest in Snapchat, Dennis Phelps (2013) notes: "We love companies that benefit from network effects. Google, Facebook and Twitter all enjoy them [...] Similar to these companies, Snapchat becomes increasingly valuable to each of its users as more and more of their friends and acquaintances sign up... such is the nature of social/mobile networks. Think Twitter... Think Instagram... Think Pinterest... and Snapchat is just getting started."

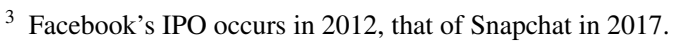




\section{Stage II: transition}

As Hammond et al. (1998) explain, which is supported by subsequent studies (e.g., Malhotra et al., 2015), decision makers, often unconsciously, only look for those pieces of information that simply reinforce their already formed, emotionallydriven, point of view (i.e., confirming evidence, a make happy bias), while (still unconsciously) conversely avoiding the information that can contradict it. In EDM, the continuous accumulation of confirming evidence can, in turn, foster similarity (Zhang \& Cueto, 2017).

As such, within the transition stage depicted in Fig. 1, when attempting to strengthen the investors' initial choice in stage I, founders of new, potentially selected Unicorns can affectively look for confirming evidence and similarities between themselves and the history of other successful Unicorns (e.g., the attempt to be acquired by big industry players). Again, through juxtaposition, this can lead to the establishment of the promising start-up as a Unicorn, thus confirming the apparent suitability of the investment choice (explained in stage I). Therefore:

Proposition 2: At the transition stage, when founders juxtapose their potentially selected Unicorn with others, confirming evidence and similarity can occur, leading to the Unicorn's establishment.

In the social media industry, for example, we remember that in 2006 Mark Zuckerberg, Facebook co-founder and current CEO, refuses a $\$ 1$ billion offer from Yahoo to buy Facebook itself, which is the most valuable Unicorn at that time. As reported by Mike Hoefflinger (2017), the former Head of Facebook's Global Business Marketing, Zuckerberg refused the offer because he thinks that Yahoo is largely undervaluing Facebook; in other words, according to Zuckerberg, offering "only" \$1 billion means having very limited knowledge about what the founder would implement in the short-term future of Facebook.

In 2013, also Snapchat's co-founder, Evan Spiegel, then refuses a relevant purchasing offer by Facebook. In this regard, Brendan Gallagher, who follows Snap Inc. from its inception to the IPO, reports that (2018: 94-95): "On November 28, Mark Zuckerberg [...] emailed Evan, saying he was interested in Snapchat [...] Days later, Evan and Bobby travelled to a private apartment in Los Angeles to meet Zuckerberg in secret. Zuckerberg asked probing questions about Snapchat and their vision for the product and company. He then wondered aloud what Snapchat might look like as a Facebook-owned company [...] Evan explained that they weren't interested in selling the company. In response, Zuckerberg showed Poke, a new Facebook app, would be released in a few days. What was it? A messaging app for disappearing photos and videos. The message was clear: join us, or we will crush you. [However] Evan believed he knew what users wanted better than Zuckerberg - or anyone at Facebook, for that matter." 


\section{Stage III: consolidation}

The initial choice of a decision maker can self-reinforce over time (e.g., Chen et al., 2015; Sydow \& Schreyögg, 2013) because of circular and selected positive feedback; and this increasingly brings her/him to discard those pieces of information that do not reinforce the circular mechanism, thus ultimately causing a decisional lock-in. Another make-happy bias, this decisional lock-in can be interrupted only because of massively negative feedback, which provokes a huge shock in the information base owned by the decision maker.

Consequently, within the consolidation stage depicted in Fig. 1, once the establishment is made, initial investors and founders can focus on continuing the growth strategy to: $a$ ) pay back the infused resources; and $b$ ) gain increasing consensus among other prospective investors. Both are particularly necessary to sustain the high costs associated with the mass communication of the Unicorns' goods/services and, at the same time, with the operational functioning of the high volumes reached (Cristofaro, 2017). To accomplish this growth and reach the legitimization needed to attract ever-increasing investment, committed founders and investors can tend to highlight those business metrics, such as users' engagement, which show the positive results for their Unicorn. In contrast, they tend to discard those metrics, such as financial ratios, which do not support their business model. In other words, the use of criteria different to those used for the evaluation of standard businesses leads to the identification of companies that can reach skyrocketing evaluations, but does not allow spotting those able to make profits in the short-medium term (Block et al., 2019).

In the consolidation stage, in substance, all the agents can become repeatedly oriented to biasedly evaluate the investment option, i.e., the Unicorn, by the self-reinforcing of the information base. This, in turn, leads to escalating their commitment (i.e., a psycho-physic bias) towards the investment alternative chosen (McCarthy et al., 1993; Staw, 1977). Consequently, a dense network among founders and investors is built; it ultimately leads the Unicorn to reinforce its position and be legitimized within the industry. Accordingly:

Proposition 3: At the consolidation stage, self-reinforcing and escalation of commitment can occur in both founders and investors of an established Unicorn, leading to the Unicorn's legitimization.

For example, as declared by Snapchat's co-founder, Spiegel: "As we're approaching 100 million daily active users in developed markets, the thing that's most exciting and most interesting is that $65 \%$ of those daily active users are creating content every day. So that's an indicator of engagement. I guess the CEO of Vodafone said recently that $75 \%$ of the upload traffic in the United Kingdom is Snapchat. So that gives you some sense of the investment that Snapchatters are making [...]" (Recode, 2016). Likewise, in the words by the investor Liew: "I actually don't think about the company's performance since it went public. I think about the performance since it was founded. That, to me, is the more relevant metric. In the spring of 2012 when we invested, it had tens of thousands of users. Today, it's in the hundreds of millions. It employs tens of thousands of people, it generates hundreds of millions of dollars, and it's touching the lives of 
a good portion of the Western world every single day. That's pretty remarkable" (Fortune, 2017).

\section{Discussion}

In line with the scholarly endeavors within the EDM literature (Barbosa et al., 2019; Sarasvathy \& Berglund, 2010), in this conceptual article, we attempt to propose a behavioral framework regarding the birth and evolution of start-ups, with a focus on Unicorns. In our three-stage framework (Fig. 1), the establishment and subsequent legitimization of a Unicorn are conceived as the potential, combined product of make-happy, sketchy-attribute, and psycho-physic biases (Zhang \& Cueto, 2017), with the first typology constituting a possible antecedent of the others.

A main determinant of the entire process is the intertwined, evolving affective state of investors and founders. Specifically, at the birth stage in our framework, investors can be emotionally pushed towards the (make-happy) recall of the vivid memories of successful Unicorns. During the juxtaposition process, they use these positive memories as a benchmark to find similarities (sketchy-attribute) with the promising start-up under evaluation; if these similarities are found, investors anchor on them (sketchy-attribute), classifying the promising start-up as a potential Unicorn that forms the investment choice.

At the transition stage, again through juxtaposition, founders search for confirming evidence (sketchy-attribute) that is able to support the initial positive affective state of the investors towards the selected Unicorn. The result of this search is, eventually, the establishment of the Unicorn; the search can happen because, also in EDM processes, people usually tend to look for similarities that can confirm prior (or lead to) positive affective states (Cristofaro, 2020).

Finally, the consolidation stage is based on the (make-happy) self-reinforcing of the already chosen investment option. Self-reinforcing, in turn, can ultimately lead to the Unicorn's legitimization, by both founders and investors, through a biased framing of gains-losses and the associated scaling up of (psycho-physic) financial commitment.

\section{Theoretical contribution}

As its main theoretical contribution, our framework provides support and improvement of the behavioral theory of the entrepreneurial firm (Dew et al., 2008). This theory, as known, proposes that entrepreneurs: "act to fabricate their own environments (however locally) and futures (however short term) through self-selected stakeholder commitments that are embodied in new organisational goals and new market segments" (p. 55).

On this basis, new-born firms are seen as loci of interaction, where boundaries between internal and external stakeholders are blurred and change over time. Thanks to these dynamics, entrepreneurial firms can tentatively produce different answers according to environmental change (Pellegrini \& Ciappei, 2015; Scafarto et al., 2019). In this regard, as per our first contribution, we assume that founders 
and investors are inter-twined agents, at least from a cognitive perspective (Bellavitis et al., 2020; Dew et al., 2009). Indeed, the different biases that emerge from one party influence the perception of the other, and vice versa, according to a co-evolutionary logic (e.g., Adinolfi, 2021; Almudi \& Fatas-Villafranca, 2021). As a result of this conceptualization, the birth and evolution of entrepreneurial firms, in this case Unicorns, are conjectured as the product of inter-related biases of founders and investors. This conjecture also provides a tentative answer to the call, by Zhang and Cueto (2017), to identify the implications of biases in entrepreneurship.

Second, to our knowledge, our study also constitutes one of the first, potential answers to Zhang and Cueto's (2017) call to investigate the interaction among biases in the entrepreneurial context. In particular, regarding our conjecture above, make-happy biases seem to have a primary role in the causation of other biases. This appears in line with the affect-as-information model (Schwarz \& Clore, 2003) and the appraisal/emotion theory (Niedenthal et al., 1999); they both advance the driving function of feelings in interpreting information and underline the intrinsic attachment of affective states to the lived experience, as also postulated by sensemaking studies (Pham et al., 2021). Moreover, this also appears in line with recent progress in the managerial decision-making literature (Bazerman \& Moore, 2013; Gino, 2013), which also advances the causal role of the affect heuristic regarding other biases (e.g., Abatecola et al., 2018; Cristofaro, 2020). In other terms, the positive affective states seemingly lead to the collection of confirming evidence, selfreinforcing processes and, ultimately, the making of risky decisions. In the case of Unicorns, this means, for example, escalating the commitment, although in the absence of positive economic outcomes.

\section{Implications for research and practice}

The conceptual framework developed, of course, also opens the door to a number of further implications both for scholars and practitioners, which are outlined below.

First, we generally believe that the EDM research movement, including the behavioral theory of the entrepreneurial firm, can further strengthen the conceptual and explanatory underpinnings about the relationship between EDM and the outcome of the start-up endeavor if embracing some core evolutionary (Hodgson, 2004; Nelson \& Winter, 1982) and co-evolutionary (Abatecola et al., 2020; Lewin \& Volberda, 1999) logics in their theoretical constructs. Based on nested levels of evolution (e.g., Johansson \& Kask, 2013; Paniccia \& Leoni, 2019), this research perspective links dynamics and competition at the system level (e.g., industry and society) with actors' path-dependent dispositions, instincts, and decision patterns at the individual and organizational levels (e.g., entrepreneurs and firms).

Hence, the evolutionary perspective can offer a way to balance to what degree change in an industry and within a firm comes from individual agency and culture (Schlaile et al., 2021), and to what degree actors' decisions and dispositions are determined and selected by the industry or market (McCarthy et al., 2010; Stoelhorst, 2008). In other words, the evolutionary logic is neither completely deterministic nor just voluntaristic, but embraces an inter-directional duality (e.g., Cafferata, 2016; Paniccia \& Baiocco, 2021). In this regard, for example, Dobson and Breslin (2013) 
map social network structures of entrepreneurship and creativity. The authors use an evolutionary approach to explain how routinized decision-making dispositions (e.g., group habits), and the consequential behavioral patterns of a workforce, evolve over time from the interaction between various actors, and in the workforce's interaction with its environment.

Second, we have positioned our work in that EDM research stream aimed at interpreting what cognitive mechanisms potentially occur between founders and investors of Unicorns when their generation and development are considered. While our proposed relationships among irrational behaviors can advance research on entrepreneurial biases, we believe that, in the future, adopting the biases in finance lens (e.g., Adomdza et al., 2016) can also result as an approach that is useful to complement the investigation of the phenomenon. Because it can focus on investors more than on entrepreneurs, this lens may highlight the presence of other inter-related biases, which are not the primary object of focus in this work. This, of course, could also open new implications for the field of entrepreneurial finance.

Third, in terms of (related) implications for practice, our proposed framework implicitly suggests that the sum of biases of investors and founders in identifying similarities (e.g., business history and/or business model features) between promising start-ups and prior successful Unicorns, let the former have greater chances of being selected and legitimized as Unicorns themselves. Again, we need to highlight that the intensive growth of these firms requires continuous and massive support from investors and founders. In fact, Lehmann et al. (2019) verify that the continuous provision of financial resources, based on equity, is pivotal to realizing and sustaining the highlighted fast growth of Unicorns. This is because: "the logic of Unicorns lies within the speed of scaling their business model" (Lehmann et al., 2019: 11), and the network effect at the basis of the firm's value spreads only through mass communication - which requires large investments in platform technology (Cavallo et al., 2019).

However, we argue, it is not just the need for continuous funding that can increase the risks for creating and sustaining Unicorns. Indeed, it can also be the reciprocal opportunism of founders and investors that can lead to financial measures being overlooked in favor of other business metrics. As Cowden et al. (2020) explain, founders of Unicorns, and their investors, implicitly agree upon opportunism. Because the venture moves fast and makes many quick decisions in its disruptive path, investors push the venture to take higher than normal risk with their money, even though they may not be up-to-date with all the market actions of the venture and its related risks. This can create the high risk of forming business bubbles potentially having a dramatic impact on the ecosystems in which both Unicorns and investors are embedded.

Indeed, without reverting to established business measures (e.g., profitability), it is likely that a Unicorn can be a victim of a bubble similar to others that occurred under the venture capital domain (e.g., dot-com companies in the late 1990s) and the broader economic environment (e.g., real estate mortgage-backed securities before the crisis in 2008). Thus, to reduce this risk, we do believe that nascent Unicorns and their investors should, in no way, discard any traditional financial measures of business performance. From the beginning, in parallel, they should carefully craft their prospective monetization mechanisms. 


\section{Limitations and conclusions}

We conjecture this article to provide a contribution to all those scholars and practitioners interested in the lively debate of how biases can affect EDM (e.g., Arend, 2020). In particular, we have outlined a tentative behavioral-based framework, consisting of three sequential stages and associated propositions, for EDM research on Unicorns. In this regard, we are conscious that, from a strictly methodological point of view, from the beginning, our attempt is designed as a conceptual start, hopefully soliciting further discussion and specific empirical analyses (Lee, 2020). Specifically, we are aware that, in the future, qualitative analyses based on inductive theory building (Pizzi et al., 2021), and on in-depth interviews with the key figures in a case (Cassell \& Bishop, 2019), may also help deepen the key cognitive issues emerging from our framework. Relatedly, and which represents another challenging research avenue per se, these kinds of analysis may help to understand: $i$ ) what cognitive strategies are guided by intuition, rationality, or reframing, respectively (Luoma \& Martela, 2020); ii) how much perceptions, conceptualized as a pre-stage (Vlačić et al., 2021) of Fellow's (2004) options, affect these strategies; iii) and, eventually, whether the decisions regarding these strategies are also impacted by noise (Kahneman et al., 2016).

Furthermore, another limitation of this work may be considered as embedded in its own value added, that is dealing with Unicorns. In fact, despite that Unicorns have been treated as an entrepreneurial species per se and some features exist detailing their uniqueness (Erdogan et al., 2016; Govindarajan et al., 2016), one could argue that it is still difficult to conceive them as a new organizational type. Thus, further studies could focus on identifying similarities among Unicorns in order to conceptualize them as a distinct business entity. This, we believe, could in turn be useful to strengthen the reliability of those studies exploring what behavioral dynamics conduct to their birth, survival, and success (Thomas \& Ritala, 2021).

In conclusion, it seems to us that understanding major cognitive mechanisms is the key to appropriately interpreting selection regimes in the Unicorn Club. Therefore, although aware of its limitations, we hope that what we propose in this article can contribute to advancing knowledge in this EDM area.

Funding Open access funding provided by Università degli Studi di Roma Tor Vergata within the CRUICARE Agreement.

Open Access This article is licensed under a Creative Commons Attribution 4.0 International License, which permits use, sharing, adaptation, distribution and reproduction in any medium or format, as long as you give appropriate credit to the original author(s) and the source, provide a link to the Creative Commons licence, and indicate if changes were made. The images or other third party material in this article are included in the article's Creative Commons licence, unless indicated otherwise in a credit line to the material. If material is not included in the article's Creative Commons licence and your intended use is not permitted by statutory regulation or exceeds the permitted use, you will need to obtain permission directly from the copyright holder. To view a copy of this licence, visit http://creativecommons.org/ licenses/by/4.0/. 


\section{References}

Abatecola, G., Breslin, D., \& Kask, J. (2020). Do organizations really co-evolve? Problematizing coevolutionary change in management and organization studies. Technological Forecasting and Social Change, 155, 119964.

Abatecola, G., Caputo, A., \& Cristofaro, M. (2018). Reviewing cognitive distortions in managerial decision making. Toward an integrative co-evolutionary framework. Journal of Management Development, 37, 409-424.

Acs, Z. J., Stam, E., Audretsch, D. B., \& O'Connor, A. (2017). The lineages of the entrepreneurial ecosystem approach. Small Business Economics, 49, 1-10.

Adinolfi, P. (2021). A journey around decision-making: Searching for the "big picture" across disciplines. European Management Journal, 39, 9-21.

Almudi, I., \& Fatas-Villafranca, F. (2021). Co-evolution in economic systems. Cambridge University Press.

Adomdza, G. K., Åstebro, T., \& Yong, K. (2016). Decision biases and entrepreneurial finance. Small Business Economics, 47, 819-834.

Aldrich, H. E., \& Ruef, M. (2018). Unicorns, gazelles, and other distractions on the way to understanding real entrepreneurship in the United States. Academy of Management Perspectives, 32, 458-472.

Arend, R. J. (2020). Getting nothing from something: Unfulfilled promises of current dominant approaches to entrepreneurial decision-making. Administrative Sciences, 10, 61.

Barbosa, S. D., Fayolle, A., \& Smith, B. R. (2019). Biased and overconfident, unbiased but going for it: How framing and anchoring affect the decision to start a new venture. Journal of Business Venturing, 34, 528-557.

Baron, R. A. (1998). Cognitive mechanisms in entrepreneurship: Why and when entrepreneurs think differently than other people. Journal of Business Venturing, 13, 275-294.

Bazerman, M. H., \& Moore, D. (2013). Judgment in managerial decision making (5th ed.). Wiley.

Bellavitis, C., Cumming, D., \& Vanacker, T. (2020). Ban, boom, and echo! Entrepreneurship and Initial Coin Offerings. Entrepreneurship Theory and Practice. https://doi.org/10.1177/1042258720940114.

Bernoster, I., Mukerjee, J., \& Thurik, R. (2020). The role of affect in entrepreneurial orientation. Small Business Economics, 54, 235-256.

Block, J., Fisch, C., Vismara, S., \& Andres, R. (2019). Private equity investment criteria: An experimental conjoint analysis of venture capital, business angels, and family offices. Journal of Corporate Finance, 58, 329-352.

Bloomberg Technology. (2017). What Snapchat's first investor saw in the company. Retrieved from https://www.youtube.com/watch?v=61-3G9OEZKE, December 3, 2019.

Busenitz, L. W., \& Barney, J. B. (1997). Differences between entrepreneurs and managers in large organizations: Biases and heuristics in strategic decision-making. Journal of Business Venturing, 12, 9-30.

Cafferata, R. (2016). Darwinist connections between the systemness of social organizations and their evolution. Journal of Management and Governance, 20, 19-44.

Caputo, A. (2016). Overcoming judgmental biases in negotiations: A scenario-based survey analysis on third party direct intervention. Journal of Business Research, 69, 4304-4312.

Caputo, A., \& Pellegrini, M. M. Eds. (2019). The anatomy of entrepreneurial decisions: Past, present and future research directions. Switzerland: Springer Nature.

Cassell, C., \& Bishop, V. (2019). Qualitative data analysis: Exploring themes, metaphors and stories. European Management Review, 16, 195-207.

Cavallo, A., Ghezzi, A., Dell'Era, C., \& Pellizzoni, E. (2019). Fostering digital entrepreneurship from startup to scaleup: The role of venture capital funds and angel groups. Technological Forecasting and Social Change, 145, 24-35.

Chen, G., Crossland, C., \& Luo, S. (2015). Making the same mistake all over again: CEO overconfidence and corporate resistance to corrective feedback. Strategic Management Journal, 36, 1513-1535.

Colombelli, A., Paolucci, E., \& Ughetto, E. (2019). Hierarchical and relational governance and the life cycle of entrepreneurial ecosystems. Small Business Economics, 52, 505-521.

Cowden, B. J., Bendickson, J. S., Bungcayao, J., \& Womack, S. (2020). Unicorns and agency theory: Agreeable moral hazard? Journal of Small Business Strategy, 30, 17-25. 
Cristofaro, M. (2017). Countervailing the liability of newness by bringing in active initial investors: The case of Facebook. Strategic Direction, 33, 1-3.

Cristofaro, M. (2020). "I feel and think, therefore I am": An affect-cognitive theory of management decision. European Management Journal, 38, 344-355.

Crunchbase (2020). The Global Unicorn Club. Retrieved from https://www.cbinsights.com/researchunicorn-companies, September 24, 2020.

De Carolis, D. M., \& Saparito, P. (2006). Social capital, cognition, and entrepreneurial opportunities: A theoretical framework. Entrepreneurship Theory and Practice, 30, 41-56.

De Massis, A., Frattini, F., \& Quillico, F. (2016). What big companies can learn from the success of the unicorns. Harvard Business Review (online), March.

De Winnaar, K., \& Scholtz, F. (2020). Entrepreneurial decision-making: New conceptual perspectives. Management Decision, 58, 1283-1300.

Dew, N., Read, S., Sarasvathy, S. D., \& Wiltbank, R. (2008). Outlines of a behavioural theory of the entrepreneurial firm. Journal of Economic Behaviour and Organization, 66, 37-59.

Dew, N., Read, S., Sarasvathy, S. D., \& Wiltbank, R. (2009). Effectual versus predictive logics in entrepreneurial decision-making: Differences between experts and novices. Journal of Business Venturing, 24, 287-309.

Dobson, S., \& Breslin, D. (2013). An evolutionary perspective on managing the ephemeral architecture of organizational creativity. International Journal of Business Environment, 5, 413-429.

Erdogan, B., Kant, R., Miller, A., \& Sprague, K. (2016). Grow fast or die slow: Why unicorns are staying private. McKinsey Quarterly, May.

Fellows, L. K. (2004). The cognitive neuroscience of human decision making: A review and conceptual framework. Behavioral and Cognitive Neuroscience Reviews, 3, 159-172.

Fichman, M., \& Levinthal, D. A. (1991). Honeymoons and the liability of adolescence: A new perspective on duration dependence in social and organizational relationships. Academy of Management Review, 16, 442-468.

Fortune (2017). Snap's Incredible, Vanishing Pile of Cash. Retrieved from https://fortune.com/2017/08/ 14/snaps-incredible-vanishing-pile-of-cash/, January 8, 2020.

Gallagher, B. (2018). How to turn down a billion dollars: The Snapchat story. St. Martin's Press.

Gigerenzer, G., \& Brighton, H. J. (2009). Homo heuristicus: Why biased minds make better inferences. Topics in Cognitive Science, 1, 107-143.

Gino F. (2013). Sidetracked. Why our decisions get derailed, and how we can stick to the plan. Cambridge, MA: Harvard Business Review Press.

Govindarajan, V., Govindarajan, T., \& Stepinski, A. (2016). Why unicorns are struggling. Harvard Business Review (online), April.

Hallen, B. L., \& Pahnke, E. C. (2016). When do entrepreneurs accurately evaluate venture capital firms' track records? A bounded rationality perspective. Academy of Management Journal, 59, 1535-1560.

Hammond, S., Keeney, R., \& Raiffa, H. (1998). The hidden traps in decision making. Harvard Business Review, 84, 118-126.

Hmieleski, K. M., \& Baron, R. A. (2009). Entrepreneurs' optimism and new venture performance: A social cognitive perspective. Academy of Management Journal, 52, 473-488.

Hodgson, G. M. (2004). The evolution of institutional economics. Routledge.

Hoefflinger, M. (2017). Becoming Facebook: The 10 challenges that defined the company that's disrupting the world. AMACOM.

Huang, L., \& Knight, A. P. (2017). Resources and relationships in entrepreneurship: An exchange Theory of the development and effects of the entrepreneur-investor relationship. Academy of Management Review, 42, 80-102.

Huang, L., \& Pearce, J. L. (2015). Managing the unknowable: The effectiveness of early-stage investor gut feel in entrepreneurial investment decisions. Administrative Science Quarterly, 60, 634-670.

Johansson, T., \& Kask, J. (2013). On the promise and premises of a Darwinian theory in research on business relationships. Industrial Marketing Management, 42, 306-315.

Josefy, M. A., Harrison, J. S., Sirmon, D. G., \& Carnes, C. (2017). Living and dying: Synthesizing the literature on firm survival and failure across stages of development. Academy of Management Annals, $11,770-799$. 
Kahneman, D., Rosenfield, A. M., Gandhi, L., \& Blaser, T. (2016). Noise. Harvard Business Review, 94, $38-46$.

Keh, H. T., Der Foo, M., \& Lim, B. C. (2002). Opportunity evaluation under risky conditions: The cognitive processes of entrepreneurs. Entrepreneurship Theory and Practice, 27, 125-148.

Kern, E. (2013). Snapchat raises $\$ 13.5$ million Series A led by Benchmark Capital. Retrieved from https://gigaom.com/2013/02/09/snapchat-raises-13-5-million-series-a-led-by-benchmark-capital/, December 32019.

Klier, H., Schwens, C., Zapkau, F. B., \& Dikova, D. (2017). Which resources matter how and where? A meta-analysis on firms' foreign establishment mode choice. Journal of Management Studies, 54, 304-339.

Krueger, N. F. (2003). The cognitive psychology of entrepreneurship. In Z. Acs \& D. B. Audretsch (Eds.), Handbook of entrepreneurship research (pp. 105-140). Springer.

Kuntze, R., \& Matulich, E. (2016). Exploring cognitive bias in entrepreneurial startup failure. Academy of Entrepreneurship Journal, 22, 54-66.

Lee, A. (2013). Welcome to the Unicorn club: Learning from billion-dollar start-ups. Retrieved from https://techcrunch.com/2013/11/02/welcome-to-the-unicorn-club/, October 5, 2018.

Lee, B. (2020). Methodology matters; Even more. European Management Review, 17, 279-284.

Lehmann, E. E., Schenkenhofer, J., \& Wirsching, K. (2019). Hidden champions and unicorns: A question of the context of human capital investment. Small Business Economics, 52, 359-374.

Lewin, A., \& Volberda, H. (1999). Prolegomena on co-evolution: A framework for research on strategy and new organizational forms. Organization Science, 10, 519-534.

Luoma J, Martela F (2020). A dual-processing view of three cognitive strategies in strategic decision making: Intuition, analytic reasoning, and reframing. Long Range Planning 102065 https://doi. org/10.1016/j.lrp.2020.102065

Malhotra, S., Zhu, P., \& Reus, T. H. (2015). Anchoring on the acquisition premium decisions of others. Strategic Management Journal, 36, 1866-1876.

McCarthy, A. M., Schoorman, F. D., \& Cooper, A. C. (1993). Reinvestment decision by entrepreneurs: Rational decision-making or escalation of commitment? Journal of Business Venturing, 8, 9-24.

McCarthy, I. P., Lawrence, T., Wixted, B., \& Gordon, B. (2010). A multidimensional conceptualization of environmental velocity. Academy of Management Review, 35, 604-626.

Mitchell, R. K., Busenitz, L., Lant, T., McDougall, P. P., Morse, E. A., \& Smith, J. B. (2002). Toward a theory of entrepreneurial cognition: Rethinking the people side of entrepreneurship research. Entrepreneurship Theory and Practice, 27, 93-104.

Mollick, E. (2020). The Unicorn's shadow: Combating the dangerous myths that hold back startups, founders, and investors. Wharton School Press.

Murnieks, C. Y., Haynie, J. M., Wiltbank, R. E., \& Harting, T. (2011). "I like how you think": Similarity as an interaction bias in the investor-entrepreneur dyad. Journal of Management Studies, $48,1533-1561$.

Murphy, P. J. (2011). A 2x2 conceptual foundation for entrepreneurial discovery theory. Entrepreneurship Theory and Practice, 35, 359-374.

Nelson, R. R., \& Winter, S. G. (1982). An evolutionary theory of economic change. Harvard University Press.

Niedenthal, P. M., Halberstadt, J. B., \& Innes-Ker, A. H. (1999). Emotional response categorization. Psychological Review, 106, 337-361.

Omorede, A., Thorgren, S., \& Wincent, J. (2015). Entrepreneurship psychology: A review. International Entrepreneurship and Management Journal, 11, 743-768.

Paniccia, P. M. A., \& Baiocco, S. (2021). Interpreting sustainable agritourism through co-evolution of social organizations. Journal of Sustainable Tourism, 29, 87-105.

Paniccia, P. M. A., \& Leoni, L. (2019). Co-evolution in tourism: The case of Albergo Diffuso. Current Issues in Tourism, 22, 1216-1243.

Pellegrini, M. M., \& Ciappei, C. (2015). Ethical judgment and radical business changes: The role of entrepreneurial perspicacity. Journal of Business Ethics, 128, 769-788.

Pham, D., Jones, P., Dobson, S., Linan, F., \& Viala, C. (2021). Entrepreneurial implementation intention as a tool to moderate the stability of entrepreneurial goal intention: A sensemaking approach. Journal of Business Research, 123, 97-105.

Phelps, D. (2013). Ten reasons why IVP invested in Snapchat. Retrieved from https://www.ivp.com/ news/press-release/ten-reasons-why-ivp-invested-in-snapchat/, October 232019. 
Pizzi, S., Corbo, L., \& Caputo, A. (2021). Fintech and SMEs sustainable business models: Reflections and considerations for a circular economy. Journal of Cleaner Production, 281, 125217.

Pontikes, E. (2012). Two sides of the same coin: How ambiguous classification affects multiple audiences' evaluations. Administrative Science Quarterly, 57, 81-118.

Recode (2016). Snapchat's three-part business model with CEO Evan Spiegel (2015 Code Conference, Day 1). Retrieved from https:/www.youtube.com/watch?v=AqPHordzhdw 2 October 23, 2019.

Robinson, A. T., \& Marino, L. D. (2015). Overconfidence and risk perceptions: Do they really matter for venture creation decisions? International Entrepreneurship and Management Journal, 11, 149-168.

Sarasvathy, S. D., \& Berglund, H. (2010). On the relevance of decision-making in entrepreneurial decision-making. In H. Landström \& F. Lohrke (Eds.), Historical foundations of entrepreneurial research (pp. 163-184). Edward Elgar.

Scafarto, F., Poggesi, S., \& Mari, M. (2019). Entrepreneurial intentions, risk-taking propensity and environmental support: The Italian experience. In The anatomy of entrepreneurial decisions: Past, present and future research directions, Caputo, A., \& Pellegrini, M. M. (Eds.). Switzerland: Springer Nature, pp. 213-234.

Schlaile, M. P., Bogner, K., \& Muelder, L. (2021). It's more than complicated! Using organizational memetics to capture the complexity of organizational culture. Journal of Business Research, $129,801-812$.

Schwarz, N., \& Clore, G. L. (2003). Mood as information 20 years later. Psychology Inquiry, 14, 296-303.

Shepherd, D. A. (2011). Multilevel entrepreneurship research: Opportunities for studying entrepreneurial decision making. Journal of Management, 37, 412-420.

Shepherd, D. A., Williams, T. A., \& Patzelt, H. (2015). Thinking about entrepreneurial decision making: Review and research agenda. Journal of Management, 41, 11-46.

Shontell, A. (2013). How Snapchat's first investor found Snapchat before anyone else. Retrieved from https://www.inc.com/alyson-shontell/how-snapchat-investor-found-snapchat-before-anyoneelse.html, December 3, 2019.

Simon, H. A. (1947). Administrative behaviour. The Free Press.

Simon, M., Houghton, S. M., \& Aquino, K. (2000). Cognitive biases, risk perception, and venture formation: How individuals decide to start companies. Journal of Business Venturing, 15, 113-134.

Soto-Simeone, A., Sirén, C., \& Antretter, T. (2020). New venture survival: A review and extension. International Journal of Management Reviews, 22, 378-407.

Stadler, C. (2016). What large companies can learn from successful unicorns. Retrieved from https://www. forbes.com/sites/christianstadler/2016/07/06/what-large-companies-can-learn-from-successfulunicorns/\#48385b66ad52, October 52018.

Staw, B. M. (1977). Escalation: The determinants of commitment to a chosen course of action. Human Relations, 30, 431-450.

Stinchcombe, A. L. (1965). Social structure and organizations. In J. March (Ed.), Handbook of Organizations (pp. 142-193). Rand McNally.

Stoelhorst, J. W. (2008). The explanatory logic and ontological commitments of generalized Darwinism. Journal of Economic Methodology, 15, 343-363.

Sydow, J., \& Schreyögg, G. (Eds.). (2013). Self-reinforcing processes in and among organizations. Palgrave.

Thomas, L. D. W., \& Ritala, P. (2021). Ecosystem legitimacy emergence. A collective action view. Journal of Management, DOI: https://doi.org/10.1177/0149206320986617.

Toft-Kehler, R., Wennberg, K., \& Kim, P. (2014). Practice makes perfect: Entrepreneurial-experience curves and venture performance. Journal of Business Venturing, 29, 453-470.

Tversky, A., \& Kahneman, D. (1974). Judgment under uncertainty: Heuristics and biases. Science, $185,1124-1131$.

Tversky, A., \& Kahneman, D. (1981). The framing of decisions and the psychology of choice. Science, 211, 453-458.

Vlačić, B., González-Loureiro, M., \& Eduardsen, J. (2021). The process of the process of internationalisation: Cognitive and behavioural perspectives in small ventures. European Journal of International Management. https://doi.org/10.1504/EJIM.2020.10027574 
Zhang, S. X., \& Cueto, J. (2017). The study of bias in entrepreneurship. Entrepreneurship Theory and Practice, 41, 419-454.

Publisher's Note Springer Nature remains neutral with regard to jurisdictional claims in published maps and institutional affiliations. 